\title{
Neorruralidad en el sudeste bonaerense. Uso del espacio y sociabilidades.
}

José Muzlera ${ }^{12}$

Resumen: La neo ruralidad es un tipo particular de migración ciudad-campo típica de las últimas décadas del siglo XX. Está motivada por la búsqueda de un cambio en la calidad de vida asociado a una vida más armónica con la naturaleza, a una convivencia más feliz y solidaria con sus vecinos y a la ausencia inseguridad. O sea a idea de un lugar más feliz. Las siguientes páginas se proponen repasar experiencias de familias neorrurales, desde el uso que hacen de los espacios, de los consumos, de los modos de vincularse con los nativos tanto en la esfera pública como en la privada y la evaluación de la experiencia migratoria.

Palabras claves: Neorruralidades; Territorio; Género; Trabajo; Esferas pública y privada.

Neo-rurality in the southeast of Buenos Aires. Use of space and sociabilities

Abstract: Neo-rurality is a particular type of city-countryside migration typical of the last decades of the 2oth century. They are motivated by the search for a change in the quality of life associated with a life more harmonious with nature, with a happy and solidary coexistence with their neighbors, with the absence of social violence and with the symbolic construction of a happier place. The following pages, from a case study of southeastern Buenos Aires, it is proposed to review

\footnotetext{
CONICET y CEAR-UNQ - Bernal - Argentina - jmuzlera@gmail.com

Deseo agradecer a la Dra. Rocío Pérez Gañan la lectura atenta y las valiosas sugerencias a este artículo.
} 
experiences of neorrural families from the use they make of spaces, consumption, ways of linking with natives in both the public and private spheres. and the evaluation of the migratory experience.

\section{Keywords: Neo-ruralities; territory; gender-work; public and private spheres}

\section{Introducción}

Las transformaciones en materia de política económica de corte neoliberal que ha experimentado la Argentina desde la las últimas décadas del pasado siglo XX tuvieron sus orígenes en tiempos del Estado burocrático autoritario durante la presidencia del general Juan Carlos Onganía, con las políticas de Adalbert Krieger Vasena al frente del Ministerio de Economía entre 1967 y 1969. Estas fueron continuadas y profundizadas por los gobiernos militares que asumieron en 1976 y con la gestión de José Alfredo Martínez de Hoz en el lugar que antes había ocupado Krieger Vasena. Pero ya disciplinados por la dictadura militar los actores sociales que se oponían a ellas, estas políticas fueron llevadas a su máxima expresión durante la década menemista, entre 1989 y 1999, esta vez con Domingo Felipe Cavallo al frente de la cartera económica. Entre 1991 y 1994, el gobierno de Carlos Saúl Menem realizó una activa transformación del marco regulatorio de la actividad económica con el fin de generar las condiciones necesarias para el desarrollo de la libre circulación de bienes, servicios y capitales. La valorización de los bienes inmateriales gracias a las modernas tecnologías constituye dinámicas centrales de lo que algunos economistas han denominado nuevo régimen de acumulación dominado por lo financiero, complementados en la producción agropecuaria por saberes y tecnologías. Este neoliberalismo económico ha llegado a tener efectos profundos e irreversibles en la estructura social agraria y en los sujetos que la componen, marcando así una nueva etapa en el desarrollo del capitalismo agrario argentino. Las transformaciones sociales, económicas y productivas asociadas al neoliberalismo plantean desafíos para pensar las dinámicas agropecuarias, el modelo productivo, los procesos por los que han atravesado los diversos agentes directamente vinculados a la actividad y las dinámicas socioeconómicas que se despliegan vinculadas al agro y a los espacios rurales. (Kay, 2008).

Neorruralidades un concepto al que a menudo se lo asocia, a nuestro entender de modo erróneo, con el de nuevas ruralidades. La cuestión de las nuevas ruralidades, también cristalizada a fines de los 90 del siglo pasado y popularizada en Latinoamérica por Norma Giarraca (2001). En Brasil, desde una 
perspectiva muy crítica, observando la realidad del país hermano, Graziano da Silva (1987) sostenía que es imposible pensar alternativas tecnológicas que no sean cada vez más dañinas dentro del sistema capitalista agrario. Años después, María José Carneiro (2013) seña, al igual que Giarracay otros autores, la dificultad creciente en esta neorruraliad de distinguir con claridad lo rural de lo urbano. El concepto en cuestión tiene sus orígenes en la sociología rural para dar cuenta de los procesos que ya no pueden ser explicados con los paradigmas existentes que oponían lo rural a lo urbano, lo moderno a lo tradicional y en los que lo agrario y lo rural se superponían. El concepto de nueva ruralidad, que como muchos otros es polisémico y con ciertas ambigüedades, hace referencia a loscambios experimentados por el medio rural latinoamericano a partir de los años ochenta del siglo XX, cuando comenzaron a hacerse más intensos los efectos de la globalización y de las políticas neoliberales. En su sentido analítico, muestra la importancia de los fenómenos alternativos a la ruralidad tradicional y en general aluden a la denominadadesagrarización y a la penetración del gran capital en la producción agraria. (Giarraca 2001, Hernández González; Meza Huacuja, 2006; Grammont, 2008; Kay, 2008; Pellón, 2015).

En este contexto, de modo simultáneo, pero sin ser exactamente parte del mismo proceso socialse da otro denominado neorruralidad que abraza una multidimensionalidad de procesos, pero que de modo sine qua non refiere a una migración ciudad campo. Estas movilidades de una u otra manera se vinculan con una revalorización y recuperación de lo que, para sus protagonistas, se supone es el deber ser y el ser tradicional de la vida agraria, con valoresvinculados a una producción artesanal rural sustentable y con una vida en armonía con la naturaleza y la comunidad en la que se inserta. La ruralidad tradicional y la vuelta al campo son conceptos que como todas las categorías nativas terminan siendo significantes con significados parcialmente diversos y de ahí las contradicciones que presenta. (Ruiz Rivera, 2009; Ruiz Rivera Delgado Campos, 2008).

Estas dos conceptualizaciones, nuevas ruralidades y neorruralidad, dan cuenta de las transformaciones agrarias producidas por la aplicación de políticas neoliberales. De allí que autores como Hernández González y Meza Huacuja (2006) consideren a la neorruralidad como parte de las nuevas ruralidades. Nosotros, como explicitamos más arriba, los entendemos como dos conceptos independientes. Uno, el de nuevas ruralidades, hace referencia a un proceso que se origina con el avance del gran capital en el agro. El otro, el de neorruralidades, alude a un movimiento sociocultural contestatario a la vida en las grandes urbes.

En línea con la propuesta de Trimano (2015b), este trabajo considera a la "neorruralidad" como una construcción con entidad teórica propia, que da 
cuenta de un proceso social que presenta una alternativa de vida, crítica al modelo urbano. La noción de neorruralidadimplica un movimiento cultural que se traduce en una migración ciudad-campo protagonizado por actores de clase media urbana ${ }^{3}$, con iniciativas vitales fundadas en la búsqueda de un cambio de vida y un acercamiento a la naturaleza y la vida en comunidad. Para Castells (2003) El "neorruralismo" se observa en parajes rurales o pueblos pequeños, definidos - por el urbanita- como bellos, exóticos y de una temporalidad asociada al "tiempo glacial".

La migración ciudad-campo es una suerte de rito de pasaje que convierte a un sujeto urbano en neorrural. Esta mudanza geográfica siempre es una decisión ampliamente meditada, que algunas veces se va realizando de a partes y que junto con bienes materiales se mudan valores, expectativas y capitales simbólicos que se pondrán en juego en los nuevos espacios residenciales y las dinámicas sociales con los nativos. Este tipo de migración no es una migración de masas de sectores subalternos que no pueden satisfacer sus condiciones mínimas de subsistencia. Son sectores de una clase media urbana que, crítica a los modos de vida en la urbe, va atrás de un sueño de una vida mejor. Así, indefectiblemente, los espacios en el que los sujetos interactúan se reconfiguran y lasestructuras productivas, económicas y sociales de los pueblos rurales argentinos experimentan transformaciones, que no siempresonarmónicas ni en una soladirección.Este proceso social, denominadonoeurralidad, en distinta medida según las localidades, se da en gran parte de los espacios agrarios y rurales argentinos. En algunos, llega a transformar la estructura demográfica local y en otros son sólo algunos casos que no afectan significativamente la vida ni la percepción de los nativos. (Llambí, 2004; Trimano, 2015b).

La neoruraliad, interpelada desde los flujos migratorios, presenta un proceso novedoso, ya que, durante la edad media y la edad moderna, la humanidad occidental fue urbanizándose. (Alcántara Ferrer, 1977; Bourdieu, 2002; Otero, 2007). En este sentido, desde el siglo XX, en el contexto latinoamericano, la Argentina fue un país de avanzada. Según diversos documentos del INDEC, en 1895, el índice de urbanización argentino era de 37,4\%. En 1914, 52,7\%. En 1947 era de 62,2\%. En 1960 la urbanización llegaba al 72\%. En 1970 al 78,5\%. Ya en 1980, el 83\% de los argentinos vivíamos conglomerados de más de 2.000

3 Retomamos la definición de clase media de Ezequiel Adamovsky (2009) que la define como a un grupo de personas directamente observable sino a una imagen mental. La clase media, más que una clase social unificada por sus propias condiciones objetivas de vida, es un conglomerado de grupos diversos, que no son trabajadores manuales ni ricos, que han adoptado una identidad subjetiva de "clase media", es decir que se piensan a sí mismos como pertenecientes a dicha clase. 
habitantes (número de habitantes que se consideran como punto de inflexión entre lo rural y lo urbano). En 1990, la población en zonas urbanas alcanza el $86,9 \%$. En 2001, la urbanización del país alcanza al 89,3\% de la población total y en 2010 el 91\% de la población argentina era urbana. Estos procesos de urbanización no se explican por la tasa de crecimiento vegetativo sino por las migraciones campo ciudad. Los motivos principales de estas movilidades fueron las posibilidades de actividades rentables que no ofrecían los entornos rurales, el acceso a servicios y la cercanía a la modernidad, entendida acríticamente como algo positivo. (Bourdieu, 2002).

Aún las migraciones ciudad-campo producto de la gran crisis económica de alcance mundial iniciada fines de 1929 fueron distintas a la neorruralidad. En ese momento no fueron voluntarias hacia un lugar ideal si no una especie de retirada compelida por la falta de empleo y redes de contención estatales hacia territorios menos mercantilizados que las grandes ciudades y con redes de contención familiar (Castel; Haroche, 2003).

Los neorurales, críticos de la vida urbana, el nivel de consumo y la impersonalidad de la vida en las grandes urbes se construyen con una alternativa nueva y cualitativamente distinta. Invierten el proceso migratorio tradicional campo - ciudady se trasladan desde la ciudad al campo. (Picciani, 2016; Rivera, 2009) En muchos casos, como el del pueblo en donde realizamos el trabajo de campo, estos flujos migratorios no llegan a transformar significativamente la composición demográfica de la sociedad receptora, pero en otros como en Villa Laguna La Brava, del Partido de Balcarce, o en Las Calles, en la zona de Traslasiera, en la Provincia de Córdoba, presentado por Trimano (2015a; 2015b) el peso demográfico de los nuevos migrados es muy significativo “(...) inmigrantes residentes (casi la mitad de la población), provenientes de grandes ciudades (Buenos Aires y Córdoba)." (Trimano, 2015b: 4).

La neoruraldiad, durante las últimas décadas, ha captado el interés del mundo académico.Se reflexiona sobre la reestructuración territorial a partir de la revalorización de los espacios rurales para nuevas actividades y las asociaciones con valores positivos. Así aparecen dos fenómenos que luego son integrados en el de neoruralidad, el de contraurbanización y de renacimiento rural. (Cloke, 1985; Ferrás Sexto, 1997; Linck, 2001; Echeverri; Ribero, 2002; Dirven, 2004; Leveau, 2009; Rivera, 2009; Morillo; Pablos, 2012; Cardoso, 2013). La realidad de los espacios agrarios está volviéndose más compleja, explicando porque esque en la década de 1990 cobran definitivameteentidad propia las nuevas ruralidades, el modelo agronegocios y las neorruralidades. (Gras; Hernández, 2016; Hüter, 2016; Muzlera, 2013; Picciani, 2016). 
Los resultados de este artículo surgen del trabajo conneorrurales de una localidad del sureste de la Provincia de Buenos Aires, Argentina, ala cual, para mantener el anonimato de los sujetos entrevistados, renombramos como El Pampero.

El objetivo del mismo es comprender los modos cómo viven la experiencia neorrural estos migrantes ciudad-campo. Para ello hemos construido una tipología de 3 categorías a partir del uso que hacen del territorio en tanto espacio social en el cual se trabaja, se consume y se está y los modos de vincularse con los nativos tanto en la esfera pública como en la privada.

La hipótesis principal es que si bien las categorías poseen poder explicativo que ya se irán desarrollando adaptarse al nuevo lugar es muy difícil y las ilusiones que motivaron la migración suelen desvanecerse con el paso del tiempo.

En 2010, este poblado contaba con 500 habitantes. Esto es un $8 \%$ menos que en el 2001 y un 5\% menos que en 1991, lo cual sugiere que la crisis de 2001 favoreció a que la localidad -un poco más protegida de la mercantilización de la vida de las grandes urbes y dada la arquitectura de las viviendas- se haya presentado como una suerte de refugio. Está ubicada a $30 \mathrm{~km}$ por ruta asfáltica de la ciudad cabecera del partido, de unos 40.000 habitantes y a $450 \mathrm{~km}$ de la ciudad de Buenos Aires. Aunque hay establecimientos de producción mixta, por sus particularidades agroecológicas, se la considera una zona de aptitud agrícola. Predominan la producción extensiva de: soja, trigo, maíz y girasol y papa.

El cierre del ramal ferroviario en la década de 1990, el acercamiento relativo (para quienes poseen movilidad propia) de la ciudad cabecera del partido y la percepción de los nativos de la falta de empleo, produce -junto con una merma del número de habitantes- la sensación de que "el pueblo va para atrás" o "el pueblo está muriéndose". Aunque no existen datos, ya que el CNP 2010 no los desagrega para esta localidad, se percibe una población envejecida. Está percepción es compartida por la gente del pueblo quien reiteradamente expresa que los jóvenes se van a estudiar y dada la falta de oportunidades ya no regresan.

Como característica común con las pequeñas localidades de la provincia de Buenos Aires, la ausencia del tren a partir de la década de 1990 ha sido un factor determinante para que la actividad económica del pueblo disminuyera. En otros tiempos, durante la primera mitad el siglo XX, el pueblo llegó a tener 2 hoteles, una cooperativa agrícola que sobrevivió hasta la década de 1990, un local de despacho de combustible, 2 talleres mecánicos y 2 chapistas, 2 clubes sociales y deportivos cada uno con su bar, 1 bar, 1 restaurante, 2 colegios primarios, 5 almacenes, 3 carnicerías y 1 tienda de ropa y mercería, entre otras instituciones y comercios. Hoy los dos hoteles están en ruinas, la cooperativa no existe, no 
hay ningún taller mecánico ni donde cargar combustible. Hoy, El Pampero no tiene un sólo bar. Carme puede comprarse sólo en un local que también vende verduras y productos de almacén. De los clubes queda uno, ya sin bar, y perdió su personalidad jurídica. Durante la década de 1980, un sacerdote de nacionalidad europeo, en gran medida con dinero que recibía de su familia, construyó -entre otras obras- un centro cultural y recreativo (hoy un galpón donde duermen trabajadores golondrinas) un jardín de infantes (hoy con 15 estudiantes) y un colegio secundario (hoy con 65 estudiantes). De los dos colegios primarios mencionados, sólo queda uno al que concurren 60 estudiantes.

Las descripciones y análisis de estas páginas están hechas desde una perspectiva metodológica cualitativa, en base a observaciones e historias de vida, clásica de los estudios de caso. Estas observaciones se caracterizan por una mirada reflexiva, en la que el acento del análisis está puesto en la comprensión de las categorías nativas y sus autores. (Geertz, 2006). La ventaja de los estudios de caso de estilo, sobre otros de mayor alcance territorial y/o de unidades de análisis, es la minuciosidad de detalle de las dinámicas sociales que posibilitan una comprensión más acabada. En palabras de Norbert Elías:

La selección de una pequeña unidad social como objeto de investigación deproblemas que se pueden detectar en una gran variedad de unidades sociales másamplias y diferenciadas posibilita la exploración minuciosa de dichos problemas, por así decirlo, con microscopio. Es factible erigir un modelo explicativo a escala reducidade una figuración que se cree universal, esto es, un modelo listo para ser contrastado,expandido o revisado según la necesidad gracias a las indagaciones en figuracionesrelacionadas a una escala más amplia. (Elías, 2003: 221).

En El Pampero identificamos 19neorrurales, personas que nacieron en ciudades grandes (o un caso en el que desarrolló más de la mitad de su vida en grandes centros urbanos) y se mudaron a este pueblo o sus alrededores en busca de una mejor calidad de vida. Las características del pueblo y las dinámicas establecidas con los nativos desde hace varios años, y con los neorrurales para la investigación en curso, permiten suponer que en el poblado no hay más neorruales que los identificados.

Las entrevistas fueron realizadas en un trabajo de campo que duró un mes durante noviembre de 2016. Esas entrevistas fueron realizadas en lugares que les eran familiares a los entrevistados y a la mayoría de ellos se los entrevistó varias veces. Las entrevistas trataron de tener un tono informal favoreciendo la comodidad del entrevistado y reforzando el vínculo de confianza entre ambos. 
Fueron mates, cenas familiares y visitas cortas en espacios y momentos de trabajo. Así y todo, no con todos se alcanzó el mismo nivel de confianza e intimidad. En general con los varones fue más fácil. Tal vez con excepción de Mariela y de Sandra. Mariela la más joven de las adultas, profesional, llegada a El Pampero hace pocos años es socia de su marido. Ambos trabajan por igual. Sandra, también profesional, es soltera. Con el resto de las mujeres, si bien siempre hubo un muy buen trato se las percibía en el rol de esposa de y no logré que tomen un rol protagónico en los encuentros en los que más de una vez no participaban más allá que para ofrecer una bebida y retirarse. Esto se verá reflejado en las selecciones de fragmentos de las entrevistas; hay quienes aparecen citados más veces porque en los encuentros han contado más cosas. La primera vez que se referencia a los entrevistados se hace una breve descripción de quienes son. Al final de trabajo se presenta una tabla con una sistematización de las características los entrevistados.

En las siguientes páginas se podrá leer el Marco de Referencia, Los Resultados con un subapartado por cada categoría construida, las Reflexiones Finales, la Bibliografía y el anexo de las entrevistas.

\section{Marco Referencial}

El fenómeno neorrual es susceptible de diversos abordajes y perspectivas. Aunque la mayoría aborda el fenómeno considerando a las personas migrantes como unidad de análisis están quienes estudian los vínculos establecidos entre noerruales y nativos (Trimano, 2015a), quienes se centran en el análisis de los flujos de mercancía ciudad-campo (Picciani, 2016) y de perspectivas múltiples como el trabajo editado por Hernández González y Meza Huacujaj (2006).

Dentro del universo de trabajos que, como el nuestro, intentan construir categorías explicativas encontramos el de Luciana Trimano (2015b) y el de María Jesús Rivera (2009). En el primero, Trimano (2015b), se reconstruye tipologías nativas: "Gringos originales", "Gringos actuales" y "Hippies". Rivera (2009), por su parte, las construye partir de la manera de irse a vivir al campo (Rivera, 2009: 419), resultando las siguientes categorías: "Distopía pragmática: espacios periurbanos, espacios de adaptación, movilidad yproximidad. El dominio del hogar", "Utopía de refugio: salvación individual, movilidad y flexibilidad espacial. Eldominio de la comunidad" y "Utopía de arraigo: cambio de vida, arraigo y distanciamiento. El dominio de lanaturaleza”.

Las categorías utilizadas por Trimano (2015b) son impensadas para nuestro análisis. En primer lugar, su unidad de análisis es el tipo de vínculo establecido 
entre nativos y los distintos neorruales (clasificándolos estos con categorías nativas). En segundo lugar, en el caso considerado para nuestra investigación, el escaso peso demográfico de los neorrurales lleva a que los nativos no construyan tipologías acerca de estos ni le dediquen atención en tanto grupo social. Si bien "todo el pueblo" los conoce y no se percibió conflicto de ningún tipo, son "ignorados" en tanto neorruales y como veremos a lo largo del trabajo, en distinta medidad, también lo son como habitantes del pueblo.

En el trabajo de María Jesús Rivera (2009), para el caso de Navarra, España, las categorías son condensadas por la autora. Al estar construidas a partir de las compresiones que los entrevistados realizaban sobre el mundo y sus propias biografías, nos brindan elementos de análisis útiles para pensar nuestro campo y construir categorías con poder explicativo para la realidad que nos toca observar.

Aunque nuestra propuesta es cercana a la de María Jesús Rivera (2009) sus categorías fueron desarrolladas para un caso puntual de la Península Ibérica y por más que el modelo agropecuario actual sea global y dominante, tiene diversas traducciones nacionales y locales, y ser este un estudio de caso, es necesario adaptar las herramientas de análisis para el contexto que pretende comprenderse.

Otros dos trabajosque nos ha sido de utilidad para interpelar nuestro campo son el de Morillo y de Pablos (2012) y el de San Agustín (2001). El primero de los dos, también mirando casos españoles, no distinguen entre tipos de neorruales, se centran en los motivos de la migración y las coincidencia ideológicas e identitarias. El de San Agustín (2001) se centra en los cambios acontecidos en las valoraciones culturales de lo rural y en las contradicciones, ambivalencias y paradojas presentes en las relaciones entre lo rural y lo urbano por parte de los neorrurales.

\section{Resultados. Categorías para acercarse a la inserción en la neorruralidad bonaerense.}

Las prácticas productivas y económicas que despliegan los actores sociales del agro implican sostener un particular modo de vida en el plano de la subjetividad y un modelo específico de desarrollo local y global en el plano estructural. Tanto los distintos modelos productivos y las dinámicas (cotidianas y a largo plazo) desarrolladas por los actores, así como los procesos de circulación de capital que ellos ponen en marcha pueden implicar diferentes usos de la tierra, diferentes lógicas de ocupación y valoración de los espacios locales, diferentes 
relaciones sociales y por lo tanto diferentes habitus con los cuales interpretaran y actuaran en el mundo (Bourdieu, 2007; Hüter, 2016). En este sentido, a partir de la observación de los modos en que estos neorrurales utilizan el espacio, las dinámicas de socialización, el momento del ciclo de vida y el relativo éxito económico hemos construido tres tipos ideales: desencantados, ilusionados y adaptados. Estas categorías pretenden tener un poder explicativo acerca de cómo es la vida de estos neourrarales y su futuro cercano.

\subsection{Desencantados}

Mudarse de la ciudad al campo no sólo es una importante inversión en lo económico sino también en lo emotivo. Y como toda inversión, los costos pueden llegar a percibirse como más que los beneficios. En estos casos abandonan esa nueva vida neorrural o evalúan abandonarla. De los 18 casos considerados en este trabajo, 4 ya han abandonado El Pampero y 4 más están evaluando hacerlo. Entre quienes ya se marcharon, dos son ex esposas de hombres que aún viven en El Pampero, la de Eugenio y la de Arturo. Ambas habían migrado con ellos y después de la disolución del vínculo de pareja se han vuelto a Buenos Aires de donde eran oriundas. Los otros dos casos son los hijos de Eugenio, que cuando llegó el momento de dejar de hogar paterno lo han hecho trasladándose a grandes ciudades del centro y norte del país. Entre quienes están evaluando irse el principal motivo es para vivir cerca de sus hijos y nietos. Ellos son los dos hombres divorciados, Eugenio y Arturo, que ya están jubilados y Mauro y la esposa. Estos son un matrimonio mayor, con nietos en Buenos Aires. En este caso si bien él sigue en actividad, su trabajo no está anclado físicamente a El Pampero. Revende de modo online artículos para explotaciones agropecuarias y se traslada para las entregas. Para este trabajo es lo mismo vivir en El Pampero o en Buenos Aires, según él mismo explicó en la entrevista. El resto de los entrevistados siguen proyectándose en El Pampero.

Vivir en el lugar no significa lo mismo para todos (Elías, 2003; Rivera, 2009). Están quienes duermen, trabajan, consumen y se esparcen en una misma localidad, quienes lo hacen parcialmente y quienes sólo duermen en El Pampero y trabajan en una ciudad o de modo on line, estos últimos están físicamente en el pueblo, pero salen poco de su casa y prácticamente no se vinculan con los nativos. Los neorrurales desencantados suelen habitar el pueblo de las últimas dos maneras descriptas "Yo casi no salgo de acá[refiriéndose a su casa]. Me gustan la paz y el paisaje." (Eugenio, 68 años, jubilado, divorciado, ex militante 
político y funcionario local, vive en 9 hectáreas a 15 kilómetros de la ciudad cabecera del partido).

"Casi no salgo de casa, me junto con dos o tres a tomar unos vinos de vez en cuando y nada más. Este pueblo está lleno de gente chata, por eso están como están. Cuando vine, hace 12 años intenté hacer un montón de cosas, después me cansé. Son unos dejados de mierda. Yo disfruto mi soledad, mis animales, mis plantas, el paisaje..." (Arturo, 73 años, jubilado,divorciado, vive una casa construida por él, en un terreno de una hectárea en las afueras de El Pampero).

En el caso de Arturo no sólo se ve como está en el pueblo sino también el desencanto con el pueblo, motivo principal de su aislamiento.

"A nosotros nos gusta mucho este lugar, pero casi no nos relacionamos con nadie, de acá. Nos llevamos bien con todo el mundo, pero no hicimos amigos. (...) Plantamos frutales y tenemos un montón de ponedoras y huerta. Nos gusta eso y todo el excedente lo regalamos o hacemos trueque. La gente nos quiere, pero no somos de salir ni de relacionarnos con nadie." (Mauro, 69 años, se dedica a vender de modo onlineinstalaciones para explotaciones agropecuarias, vive en las afueras del pueblo en una casa rodeada de árboles que no se ve desde la calle).

Para los desencantados, los vínculos sociales que establecen con los locales son escasos y débiles. En el caso de Arturo, inclusive, de franco rechazo. En las entrevistas, dejan ver una valorización del paisaje y su belleza, pero no con los nativos y sus modos de vida. El entorno natural es considerado como un recurso a su disposición, para su uso y disfrute, a través de diferentes prácticas espaciales y experiencias estéticas. (Rivera, 2009) Hay un goce y un uso del entorno, pero no un sentirse parte del mismo. No se integran ni con el medio natural ni con la comunidad. Tres de ellos (Arturo, Mauro y su Sra.) producen alimentos para autoconsumo, no así Eugenio. Ninguno trabaja en El Pampero, ni consume allí más que cosas aisladas, ni se vincula con los nativos. Todos ellos están evaluando irse del pueblo.

El pueblo o el campo (cercano al pueblo) es sólo el lugar para ir a dormir o para refugiarse y aislarse, para contemplar el paisaje, pero no para establecer ningún tipo de vínculos. Trabajan en Buenos Aires, en la ciudad cabecera del partido a 40 kilómetros del pueblo o por Internet. Si bien sólo uno de ellos valora negativamente la calidad de vida local, todos desean dejar la la vida en 
el pueblo y volverse a la ciudad. Aún aun valorando positivamente la vida en El Pampero, valoran más la cercanía de hijos y nietos que el entorno físico local.

Estas migraciones fueron parte de una planificación y un proceso. Fueron proyectos de vida que, para esta categoría, no acabaron de la manera esperada. "No sé cuántas veces pasábamos por acá, camino a la costa, y nos daban ganas de mudarnos. Algunas veces, antes de seguir camino dábamos una vuelta. Otras, inclusive estábamos en la costa y veníamos a pasar el día" (Mauro).

"Yo manejaba un transporte y tenía un amigo que se había comprado una casita y siempre me hablaba de lo lindo que era, de la paz que se respiraba y me calentó la cabeza. Yo vivía cerca de Ezeiza y estaba podrido de la inseguridad. Un día que andaba cerca nos vinimos a conocer su casa y comer un asadito y me convenció. (...) Y así fue, de a poquito lo fui edificando y cuando me jubilé me mudé con mi Sra." (Arturo).

De los de esta categoría Eugenio y su esposa son los únicos que migraron relativamente jóvenes y con hijos en edad escolar. Se mudaron hace aproximadamente 25 años, dejando atrás una vida de bienestar económico como pequeños empresarios del turismo (dueños de un hotel) para dedicarse a la política. Eugenio vivió la actividad política con la convicción que ese era el modo de construir un mundo mejor.

"Era joven, idealista, hoy no lo haría. El mundo sigue igual y yo perdí todo, ni familia me queda. En su momento estaba muy entusiasmado, me metí hasta el cuello, y después no era fácil salir. Iba viendo que la cosa no era como la había pensado, pero ya no era fácil salir y fui perdiendo mi mujer, mis hijos y después mí amigos." (Eugenio).

Arturo, Mauro y la esposa de Mauro se mudaron ya grandes, después de los 60 años. Arturo ya jubilado. En todos ellos hay un desencanto de la comunidad de destino. Excepto Eugenio todo el resto valoraban negativamente los ritmos de vida de la gran ciudad e imaginaban una vida en el campo, o en un pueblo chico como El Pampero, más armónica e integrada con la comunidad local, menos estresante y más sana.

"Lo veíamos tranquilo... los chicos en la calle, gente en la vereda, las sierras de fondo... Pero ya hace 5 años que estamos y en parte por la nieta que está en Buenos Aires, en parte porque nos aburrimos... Con la gente de acá está todo bien, pero no tenemos un solo amigo. Ya estamos pensando en volvernos, el tema es que esta casa no se la vendés a nadie" (Mauro). 
A pesar de que la mudanza ciudad-campo fue un proceso que llevó años, la evaluación del destino, lo que se imaginaron respecto a cómo sería la vida en El Pampero, no se correspondió con la experiencia de vida posterior. Altas exceptivas respecto a la participación en actividades colectivas para mejorar el hábitat han frustrado la ilusión de esa comunidad imaginada, armónica, pequeña y con altos niveles de integración y cooperación. Esaimagen de arcadia pastorial, en palabras de Trimano (2015b), resultó no sólo errónea sino contraproducente. La desilusión los llevó a un estado de frustración y desencanto que volvió insostenible la vida neorrural. Este desencanto, como veremos con las mujeres de la próxima categoría, parece ser más fuerte para ellas que para ellos. Los varones, en líneas generales, parecen poder vincularse mejor por vía del trabajo y tener menos expectativa respecto a la profundidad o calidad de los vínculos afectivos.

Una característica común entre casi todos los neorruraleses es la noción de solidaridad y el compromiso social. Eugenio, por ejemplo, dejó su vida familiar por un proyecto de militancia política. Mauro migró a Francia para vivir y participar de los acontecimientos del 68, años después volvió a la Argentina y ayudó alojando a refugiados políticos latinoamericanos; sabiéndose perseguido deja su casa y el trabajo y se muda a Salta para ser entrenado en el ERP4 ${ }^{4}$ Con la vuelta de la democracia realizó trabajo social en villas. En El Pampero, produce huevos y fruta orgánica y la regala a gente de bajos recursos.

Arturo, al poco tiempo de llegar, y a raíz de una intoxicación por agro tóxicos que dejó a su esposa internada 3 meses en Buenos Aires y con secuelas durante 2 años más, organizó una pequeña ONG que logró prohibir las fumigaciones aéreas cerca del pueblo.

"Ya me cansé, son una manga de pelotudos, el glifosato les quemó la cabeza a todos. No hacen nada, viven para la mierda y no se mueven. Los albañiles no trabajan bien, los pintores son horribles, electricistas no hay, como ciudadanos se dejan avasallar en sus derechos, es un pueblo de mierda. ¡Hice un esfuerzo muy grande para parar las fumigaciones y conseguir la adhesión de la gente de acá!(...) Yo no participé más y nadie hizo nada. (...) Por mí que se jodan. En Buenos Aires capaz que te mata un motochorro, pero acá te

4 El Ejército Revolucionario del Pueblo (ERP) fue una organización guerrillera argentina, que constituyó la estructura militar del Partido Revolucionario de los Trabajadores, de orientación marxista, liderado por Mario Roberto Santucho durante la década del 70. Hacia principios de 1977 fue desarticulado por las Fuerzas Armadas como consecuencia del Operativo Independencia (1975) y de la dictadura autodenominada Proceso de Reorganización Nacional que mató a su líder en 1976. 
envenenan los sojeros y nadie se mueve. Allá de última tengo a mi hijo y mi nieto. No creo bancármela mucho más acá." (Arturo).

Estos neorruales, a los que llamamos desencantados, no tienen una inserción marcada ni en la esfera pública ni en la privada. Su uso del espacio rural es dormitorio o refugio, disfrutan de la contemplación del paisaje y en alguna medida los recursos naturales, pero no logran integrase con la comunidad local ni al ambiente natural. La concepción de la naturaleza es la de algo externo a ellos. Esta desintegración los frustra, y esta frustración se agrava porque El Pampero, en tanto comunidad imaginada en los momentos previos a la migración, era una comunidad con fuertes niveles de integración y solidaridad.

\section{2. llusionados}

Los ilusionados son una categoría de neorrurales con otros modos de ser y estar en pueblo respecto a los desencantados. Poseen un mayor nivel de inserción en el terreno de lo laboral, trabajan y consumen en él. Las actividades productivas de los ilusionados son espacialmente situadas, a diferencias de los neorrurales desencantados cuyas actividades productivas eran situadas en una ciudad a la que se trasladaban o de modo online. De los 7 casos de nuestro trabajo de campo que se ubican en esta categoría, sólo 2 trabajan en relación de dependencia, Carlos y Clara. Élde 35 años y ella de 32 están casados, tienen dos hijos de 10 y 7 años. Carlos trabaja en un centro informático de una gran empresa que tiene el centro de cómputos en Buenos Aires. Está entre 3 y 5 días por semana en Buenos Aires y el resto en El Pampero. Estos tiempos dependen de las exigencias y necesidades de la empresa. Cuando está en el pueblo trabaja bajo la modalidad home office. Clara es maestra en la escuela local y voluntaria en la Sociedad de Fomento. Su trabajo, los hijos escolarizados y la Sociedad de Fomento son determinantes para la inserción de Clara en la vida local. Carlos se suma a ella cuando está a través de la su familia. Pero esta inserción no es "natural" suele ser conciente y como todo lo vinculado a la neorruralidad producto de un esfuerzo del que se espera ver frutos en un futuro no muy lejano. Veamos el ejemplo de Sandra. Ella Nació en una ciudad del sudeste de la provincia de Buenos Aires, de muy pequeña se fue a vivir a la ciudad cabecera del partido y cuando llegó el momento de cursar sus estudios universitarios se fue. Estuvo algunos años en Buenos Aires y 15 en Europa. Hace 6 decidió volverse y volverse al campo. Al momento de las entrevistas tenía 54 años, 
era ex CEO de una multinacional y ahora tiene un vivero y está armando un pequeño emprendimiento turístico. Vive en un campo de 27 hectáreas a 8 kilómetros de El Pampero.

“(...) trato de comprar todo acá, pero hay cosas que no hay y esas las compro en Mar del Plata. Me gusta integrarme con la gente de acá, las cosas de comida las compro todas en el pueblo. (...) la gente de acá es difícil, no valoran lo que tienen, yo les vendo una planta de la misma calidad y más barata y son capaces de ir a comprar a Mar del Plata más caro. Pero eso no me pasa sólo a mí, eh. Eso le pasa a todo el mundo. La gente de acá no tienen conciencia de comunidad, son muy yo-yo, muy egoístas si querés... es como si se avergonzasen y para darse status consumen en otro lado" (Sandra).

A diferencia de los desencantados, los ilusionados establecen una mayor integración con el lugar sobre todo en lo que es parte de la esfera pública, el trabajo, el comercio y acciones de trabajo social solidario, pero no logran desarrollar vínculos afectivos profundos. Suelen establecer buenos vínculos, pero siempre son percibidos como extranjeros. Esta última particularidad se da en varones y mujeres, pero son las mujeres quienes más lo padecen o al menos quienes más reflexionan sobre esto.

"Con la gente de acá nos llevamos genial. (...) Yo tengo una personalidad especial, yo vine con un perfil bajo, barro el piso y no le decía a nadie que era arquitecta.(...) Acá no tengo ninguna amiga, pero no por problemas, sino porque nos pasamos trabajando todo el día. Ni siquiera puedo ver a mis amigas de toda la vida. (...)yo respeto las diferencias, puedo llevarme bien siendo distintos. Acá hay mujeres de mi edad que ya son abuelas o a la tarde ven la novela, yo jamás miro tele." (Mariela, 35 años, comparte el tambo, la producción de quesos y la fábrica de plásticos con su marido, desde que llegó ha ejercido de arquitecta, pero no le ha cobrado a quien no podía pagarle, vive en 7 hectáreas propias en las afueras de El Pampero).

Este sentirse de otro lado también le sucede a Sandra.

“Tanto El Pampero como la [acá refiere a la cabecera de partido]son lugares muy cerrados, de lo más cerrado en los que me tocó vivir. (...) Tengo amigas de toda la vida, pero hay como una barrera que es muy difícil pasar. Está todo bien, nos tomamos unos mates, pero hay algún lugar de la intimidad a 
la que no me es fácil llegar. Y si aún están casadas, peor. Siento como si a los maridos no les gustara que se juntase con una loca, solterona que anduvo por el mundo. (Sandra).

Milton Santos (1996) sostiene que las acciones vinculadas al trabajo, son cada vez más ajenas a los fines propios del hombre y del lugar porque suelen obedecer a un proyecto ajeno a quienes las ejecutan. Esta reflexión no pareciera describir a esta categoría de neorrurales. Los ilusionados se identifican con su trabajo, se realizan en él.

"Mis amigas se la pasan viajando por el mundo y nosotros, ni por plata ni por tiempo, podemos irnos de acá más de unas cuantas horas. Igual, no me quejo, vinimos por elección propia, no por necesidad. Queríamos un lugar de campo, cerca del mar. Además, necesitábamos buenas rutas por el plástico y eso lo logramos" (Mariela).

"A mí me da mucha satisfacción tener un buen trato con el cliente. Acá dejamos todo abierto y la gente pasa y charlamos. Es la simpleza de tener la voluntad de ponerse al servicio del que quiere comprar algo, de escuchar al otro. No es sólo por plata, sino también por el respeto a lo que hago y por el que vienen a comprar" (Hernán).

"El vivero no está yendo bien, pero habrá que buscarle la vuelta. Ahora estoy acondicionando la casa para el turismo. Irme de acá no es una opción. Amo el lugar y trabajar para mí. Ser la empresaria de uno mismo y vivir en comunión con el lugar produce una sensación de plenitud" (Sandra).

Los ilusionados, están en una franja etaria intermedia entre los desencantados y los adaptados, tienen entre 30 y 55 años y parecieran ser los de mayor poder de consumo de las 3 categorías presentadas. Al igual que los desencantados hay una valoración negativa de la calidad y el ritmo de vida en las grandes urbes y la mayoría de ellos, como los desencantados, poseen una marcada tendencia a la solidaridad.

Martina es católica y de chica participaba activamente de la catequesis y demás actividades parroquiales. Le gustaba la abogacía y defender a la gente de las injusticias. En 1982, cuando debió comenzar sus estudios universitarios, el miedo de sus padres por la situación política del país provocó que en lugar de

5 Entre el 24 de marzo de 1976 y el 10 de diciembre de 1983 la Argentina padeció una violenta dictadura militar que según estimaciones de organismos internacionales de derechos humanos dejó como saldo 30 
mudarse a La Plata se mudase a Tandil y como allí no existía la carrera de derecho comenzó a estudiar ingeniería en sistemas. En Tandil, mientras estudiaba, comenzó a militar y conoció a Juan Carlos Pugliese (entonces intendente) que con el regreso de la democracia fue presidente de la Honorable Cámara de Diputados. 1984 no fue sólo un año vertiginoso para el país, también lo fue para Martina. Comenzó a trabajar en el Congreso de la Nación, buscando leyes para que los diputados pudiesen ver los antecedentes de las que se debatían. Fue becada para comenzar a estudiar abogacía en la UCA y comenzó a hacer trabajo social en villas miseria de la Ciudad de Buenos Aires. Comienza así el primer episodio de una dinámica que volverá a repetirse: compromiso, fascinación, colapso y comienzo de una nueva etapa, casi una nueva vida.

"Ir a la villa y ver el perro muerto en el charco, los nenes descalzos y desnutridos, a mí me superó. Tuve que tomar distancia porque eso a mí me superó. No lo aguanté. La verdad es que se hacían cosas, había logros, pero no pude valorarlos." (Sandra)

Más o menos al mismo tiempo deja el trabajo en la legislatura y comienza a trabajar para UNICEF Argentina (Fondo de las Naciones Unidas para la Infancia - Argentina) en barrios del Gran Buenos Aires. "No me banqué trabajar en la legislatura.... Era muy joven y me faltaba madurez para separar la política de los políticos"

En 1994, comenzó a trabajar en una AFJP (Administradora de Fondos de Jubilaciones y Pensiones). Diez meses después, se organizan las ART (Aseguradora de Riesgo de Trabajo) y se entrenó para cómo -desde lo privado- trabajar desde "el servicio hacia los otros". "Me tocó ser la jefa de un equipo y fue una experiencia fantástica. Interactuaban con los directores de recursos humanos de las empresas y las necesidades del personal. Pero me cargaba todo encima, no soportaba una necesidad pendiente de alguien y no paraba. Una madrugada me sacaron en una ambulancia. Había colapsado y después de 15 días de internación, ya con el alta renuncié."

Haciendo referencia a El Pampero, dice: "Quise hace algo social en el pueblo pero nadie participa. Es muy frustrante."(Sandra).

También Hernán y Mariela tienen un pasado de militancia social.

"En Altamirano educamos a la gente para reciclar. Les explicábamos... habíamos puesto por todo el pueblo bolsones, con plata de nuestro bolsillo, 
compramos bolsones de arena y pusimos carteles en todo el pueblo. Reciclábamos envases de tetra, vidrio, cartón, plástico. (...) Cuando se llenaban, se vendían en público y esa plata se invertía en materiales para la escuela. Se publicaban las facturas en todos lados. Se compraron los equipos de básquet y beisbol para todo el colegio, se armó la cancha de básquet. Y eso la gente lo veía y lo agradecía. (...) Acá no nos involucramos tanto en ese sentido. (Hernán).

La relación con la naturaleza de los ilusionados no supera el lugar del observador que construye paisaje que usufructúa dinámicas de integración y explotación respetuosa. (Williams, 2001).

"Vivir en este campo... no sé cómo explicarlo... es mágico. Levantarte a la mañana y ver las sierras, las heladas, la vida misma. Me llena de vida, después de tanto peregrinar encontré mi lugar en el mundo y no me voy más" (Sandra).

“(...) Vivir en el campo, para mí, es hermoso! ¿Si de algo no me arrepiento es haberme venido a vivir al campo.

(...) Sí, claro, a las terneras la dejamos para el tambo y los novillos por ahora los dejamos disfrutar de la vida (risas). No es que estemos en contra de que los maten y los coman, pero nos da pena. Son seres vivos y los vimos nacer. Algún día los venderemos, mientras podamos seguir manteniéndolos los tendremos comiendo pasto en el fondo" (Mariela).

Del mismo modo que los desencantados la conversión a la neorruralidad no fue una decisión puntual ni algo que se diera de un día para el otro.

"A veces siento que todo lo que hice en mi vida era un camino para llegar a acá. Esta casa era de mi abuelo y siempre fue especial. Un día sentí que había llegado el momento, pero fue como la concreción de un proceso de años... de siempre. Tomé la decisión en marzo de 2010 y comencé a preparar mi ausencia durante 6 meses. En octubre de ese año, me volví para instalarse acá, a $25 \mathrm{~km}$ de la ciudad" (Sandra).

También para Hernán y Mariela la neorruralidad fue un proceso. Ellos vivían en Buenos Aires y mientras Mariela estudiaba Arquitectura Hernán trabajaba en su propia fábrica de plásticos. Los fines de semana salían a andar en bicicicleta por la zona de la ruta y se les ocurrió comenzar a plantar zapallos. Así fue como los fines de semana se los dedicaban al ciclismo y a los zapallos. 
Cuando ella terminó de cursar se mudaron a una localidad de 2.500 habitantes a $80 \mathrm{~km}$ de Buenos Aires. Alquilaron una casaen el pueblo, no en el campo, y la fábrica de plásticos la mantenían en un galpón en Quilmes. En 2008, se mudaros a un pueblito de 250 habitantes a $10 \mathrm{~km}$ del anterior en donde compraron una quinta de 1 hectárea. Mudaron la fábrica de plástico y tuvieron la primera vaca lechera. A partir de ese momento se propusieron no sólo vivir en el campo sino también vivir de él.

Las críticas al modelo de vida urbana no sólo alcanzan a la inseguridad, el tráfico y el estrés cuestionan también la falta de independencia laboral y los altos niveles de mercantilización. El pueblo es un refugio físico y simbólico. El menor número de habitantes y su entorno hacen de él el espacio ideal para establecer relaciones vecinales basadas en la espontaneidad, el conocimiento y la confianza mutua, por oposición al tipo de relaciones impuestas por el propio ritmo y dinámica de la ciudad (Rivera, 2009).

"No somos grandes consumidores. Tratamos de hacernos la verdura y todo lo que podemos. También hacemos mucho trueque (queso por chorizos, por huevos, por pollos, por fruta, por algo de quinta que no llegamos) y la gente se pone muy contenta, porque acá no están acostumbrados al trueque. También lo hacemos con el plástico, inclusive hasta por maíz. El trueque es fantástico, sobre todo con gente honesta, te hace sentir que haces las cosas bien. (Hernán).

A diferencia de los desencantados, los ilusionados perciben que "el precio" de la migración fue una "buena inversión" el desarrollo de lazos afectivos más sólidos y el alejamiento de su familia y amigos de origen son elementos negativos que esperan solucionar en el futuro, pero que no invierten el resultado positivo del balance personal.

\subsection{Adaptados}

Habría una tercera categoría de neorrurales, la de quienes no sólo se insertan en la esfera pública trabajando y consumiendo en El Pampero, sino que también logran un nivel de inserción en la esfera de la vida privada. Sólo hemos encontrado 2casosde estos entre los 18 considerados para este artículo, Ramón de 37 años y Miguel de 34. Estos hermanos han tenido contacto con el pueblo desde pequeños, porque su abuelo paterno vivía ahí y ambos se casaron con una nativa. De las tres categorías consideradas, los adaptados parecieran ser las de menor poder adquisitivo. Son cuentapropistas del rubro construcción, changas 
de campo y doman caballos. Ninguno tiene vehículo a motor propio (sí caballos y bicicletas). Trabajan en el pueblo o por la zona y todo el consumo cotidiano lo realizan en El Pampero. Uno de los dos se presentó con una lista independiente para ser delegado municipal con una plataforma inspirada en el ecologismo inglés (vivieron 12 años en Londres) y perdió por 3 votos. El eje de su campaña estuvo centrado en la contaminación y la destrucción del medio ambiente provocada por la agricultura extensiva.

Vivir en El Pampero y hacer lo que hacen fue una elección. El pasaporte europeo obtenido por línea materna les permitió a los 6 hermanos, madre y padre vivir 12 años en Londres. 2 siguen viviendo allá, 1 en Buenos Aires, 1 en Alemania y 2 en el Pampero. El consumismo, el estrés, el anonimato y la falta de solidaridad, es una crítica que le hacen los 4 hermanos a los que pudimos entrevistar tanto a Londres como a Buenos Aires.

Ramón, de 37 años, está en pareja y sin hijos propios, pero hace de padre de una hija adolescente de su compañera. Doma caballos y hace "changas" de albañilería y pintura, eventualmente trabaja como jornalero.

"Este lugar lo quise desde chico. No es fácil de explicar, pero, aunque me mudé recién a los 20 es como si siempre hubiese sido de acá. Nací en Buenos Aires, a los diez años nos fuimos a Londres, pero siempre me sentí de acá. (...) Con la guita nos la vamos rebuscando. Es una elección vivir en paz o malgastar la vida ganando plata... acá hacemos de todo. Lo que más me gusta son los caballos, pero el resto no me molesta" (Ramón).

En una entrevista, una de las dos hermanas (no considerada neorrural para este trabajo) nos decía "A nosotras[refiriéndose a ella y la otra hermana mujer] también nos encanta El Pampero, pero acá una mujer no tiene muchas opciones. Vivimos más o menos mitad del año en Londres trabajando de camareras, tal vez un poco más, y el resto venimos acá de vacaciones. (Ximena, 30 años).

Miguel de 34 años, 2 hijos de 6 y 4, doma caballos y hace "changas" de albañilería y pintura, eventualmente trabaja como jornalero y tiene una visión muy similar a la de Ramón.

"Yo priorizo vivir acá, almorzar en casa, cenar en casa, salir a la calle tranquilo. No tenemos ni auto ni moto, pero acá no hacen falta. Nos gusta que los chicos crezcan acá. (...) Uno no se lleva bien con todo el mundo, el pueblo es como cualquier lado, hay gente buena e hijos de puta... pero te conocés. Viste lo que dicen 'Pueblo chico, infierno grande' y es así.' (Miguel). 
El vínculo con la naturaleza revista un carácter más integrado, la posición menos de observadores externos y de mayor integración.

"Una de las cosas que más me molesta de acá son los productores agropecuarios. Riegan con millones de litros de agua y las napas bajan y bajan, el agua ya no se puede tomar (está contaminada con arsénico y agroquímicos), a la biodiversidad la hacen mierda y a nosotros nos matan de cáncer. (...)Como son los que tienen la plata mueven la economía del pueblo, pero visto desde ahí la calidad de vida acá es una mierda. (...) Me da bronca porque nosotros nos conformamos con poco y somos felices. Si los ricos se conformasen con menos, todos seriamos más felices. En general la gente del pueblo no es consciente de esto." (Ramón).

Los adaptados, no parecen tan felices como los ilusionados, pero el balance entre vivir en una gran ciudad y en el pueblo parece ser |positivo. Su nivel de consumo es el menor de las tres categorías analizadas. Están claramente insertos tanto en la esfera pública como en la privada. De las tres categorías son los que presentan un vínculo más armónico con la naturaleza.

Hay un último caso, el de Federica. Ella es la madre de Ramón y Miguel, es viuda y vive en el pueblo. Le gusta el lugar, consume allí, pero no tienen prácticamente vínculo con nadie más allá de sus hijos. Al no estar arrepentida de la elección ni planear irse, no encajaría con los desencantados, pero tienen un uso del pueblo más como refugio. Tiene un bajo nivel de consumo y producción de verduras y hortalizas propias con lo cuál no hemos podido categorizarla.

\section{Reflexiones finales}

Los neorrurales son sujetos de origen clase media urbana que abandonan la vida en la ciudad para buscar, en espacios rurales, una mejor calidad de vida. El momento de la migración ciudad campo, que en algunos casos se entiende como un proceso y en otros se da en un día puntual, aunque en todos los casos son decisiones largamente meditadas. Estos cambios en las dinámicas de vida suelen darse en la juventud (donde suelen estar solteros o en pareja sin hijos o hijos chicos) o en la adultez. La mudanza ciudad-campo, que dará como resultado la transformación en un neorrural, implica una inversión de riesgo multidmensional (económica, identitaria, cultural y afectiva); es por esto que la decisión suele ser sumamente meditada y se toma en los momentos del ciclo de vida en que correr riesgoses menos peligroso. 
Durante la juventud, cuando aún no se tienen hijos, al no haber carga familiar el margen de libertad es más grande y las consecuencias negativas, si existiesen, sólo recaerían el protagonista. Por otra parte, está la sensación de "aún se puede volver a empezar". En la adultez, el otro momento en que se producen estas migraciones, es la etapa del "nido vacío" cuando los hijos ya se han emancipado del hogar paterno y existe una ventaja respecto los migrantes jóvenes sin hijos, no se pone en riesgo los medios de subsistencia (unos vivían de la jubilación y otros mantenían su actividad principal anterior y por lo tanto su medio de ingresos).

Aunque los miembros de las tres subcategorías de neorrurales valoran negativamente la vida en las grandes urbes, de modo inverso a la sensación de soledad, el rechazo hacia ellas iría demenor a mayor comenzando por los desencantados, siguiendo por los ilusionados hasta llegar a los adaptados.

Como parte de la crítica ideológica a la vida de las grandes urbes, sobre todo entre los ilusionados y los adaptados, se observa una dinámica de consumo moderada (ropa, autos, electrodomésticos, celulares, etc.). Esto, al menos entre los ilusionados se explica más por una elección ideológica y estética que por la imposibilidad material de acceder a mercancías. Para el caso de los adaptados, si bien exponen una crítica a la sociedad de consumo y presentan la austeridad como un valor, un mayor nivel de consumo -al menos en lo inmediato- pareciera no ser una opción.

Los integrantes de las tres subcategorías propuestas, presentan lógicas productivas y dinámicas culturales opuestas a las del agribusiness. Todos se manifiestan en contra de la acumulación de riquezas como un fin, de no practicar actividades productivas sustentables y de los altos niveles de mercantilización (que asocian a la vida urbana moderna y rural del agribusiness).

El compromiso social, la generación de prácticas colectivas en pos de una sociedad mejor, es una característica de casi todos los casos considerados. La conciencia social y solidaria es un elemento común, en particular entre los desencantados y los ilusionados.

El desarrollo de vínculos afectivos profundos es difícil. En las comunidades rurales observadas estos vínculos parecieran desarrollarse en la infancia o por medio de lazos de parentesco, siendo casi imposible que esto suceda después. Entre la primera versión de este trabajo y ésta, Miguel se separó, pero no parece haber perdido el grado de intimidad con sus amigos locales.

El trabajo de campo lleva a la construcción de tres categorías de neorrurales: desencantados, ilusionados y adaptados. Las dimensiones consideradas fueron principalmente el uso que hacen de los espacios y su vínculo con el medio 
ambiente, los consumos, los modos de vincularse con los nativos tanto en la esfera pública como en la privada y la autoevaluación de la experiencia migratoria. Es difícil, por el momento, establecer si esta última dimensión es una variable dependiente de las otras. Creemos que sí, pero sólo en alguna medida. La adaptación a la nueva vida no es fácil y -al menos en nuestro caso de estudio- sólo quienes han construido una familia con una nativa han podido lograrlo plenamente. Una vez logrado el "status" de adaptado es independiente del cónyuge. La sensación de soledad producida por sentirse distinto y no integrado a la gente del pueblo, que se acrecienta cuando hijos y nietos están lejos, es determinante para la sensación de frustración frente a la opción de vida neorrural y está íntimamente vinculada a la categoría de neorrurales (inexistente en los adaptados, moderada en los ilusionados y fuerte en los desencantados) y esta -casi ontológicamente- al nivel de inserción. Los desencantados tienen un muy bajo nivel de inserción, usan el campo y el pueblo como un lugar donde estar en soledad. Los ilusionados han logrado una marcada inserción en lo laboral, en el consumo local, en la vida pública en general, pero no han logrado un desarrollo de vínculos profundos en el plano afectivo. Los adaptaos han logrado el desarrollo de vínculos afectivos y en lo que a intercambios mercantiles se refiere también son los más integrados de las tres categorías de neorruralidad propuestas.

Los neorrurales, junto con los marcados niveles de compromiso social, presentan altos niveles de individuación, entendida esta característica como la posibilidad de los sujetos de ser hacedores responsables de sus propias biografías. Todos ellos han tenido un considerable nivel de autonomía para decidir dónde y cómo querían vivir. Son sujetos a los que no les tienta el riesgo económico o empresarial. La adrenalina asociada a las inversiones les produce más aversión que afición. La elección por convertirse en pequeños empresarios, generalmente sin mano de obra asalariada, se explica más por un anhelo de independencia (asociada a la calidad de vida) que por el afán de lucro derivado de evitar la apropiación de la plusvalía por parte de un otro. Son austeros en sus inversiones y en sus consumos. Hay en sus prácticas empresariales, que buscan más seguridad que éxito, cierta crítica a la condición de incertidumbre típica de esta modernidad.

\section{Referencias}

ALCÁNTARA FERRER, Sergio. Civilización, urbanización y megalopolización ¿Etapas de un mismo proceso? Diálogos: Artes, Letras, Ciencias humanas. El Colegio de México v. 13, n. 3, mayo - junio 77, pp. 16-22. Disponível em: <http://www.jstor.org/ stable/27933562>. Acesso em: 10 set. 2019. 
BOURDIEU, Pierre. El baile de los solteros. Barcelona, Anagrama, 2002.

BOURDIEU, Pierre. El sentido práctico. Buenos Aires, Siglo XXI Editores, 2007.

CARDOSO, María Mercedes. Contraurbanización en el sistema urbano argentino. El rol de los pueblos grandes en el Área Metropolitana de Santa Fe. En Programa Nacional. Olimpíada de Geografía de la República Argentina 2013. pp. 121-128. Santa Fe, Universidad Nacional del Litoral, 2013.

CARNEIRO, María José. Ruralidade: novas identidades em construção. Estudos Sociedade e Agricultura, v. 6, n. 2, 1998, pp. 53-75.

CASTEL, Robert; HAROCHE, Claudine. Propiedad privada, propiedad social, propiedad de sí mismo. Conversaciones sobre la construcción del individuo moderno. Rosario, Argentina, Ed. Homo Sapiens. 2003.

CASTELLS, Manuel. El reverdecimiento del yo: el movimiento ecologista. La factoría, v. 5, Febrero - Mayo 1998, pp. 1-20.

CLOKE, Paul. Counterurbanisation: a Rural Perspective. Geography, v. 70, n 1, January 1985 , pp. 13-23

DIRVEN, Martine. El empleo rural no agrícola y la diversidad rural. Revista de la CEPAL, n. 83, Agosto 2004, pp. 49-69.

ECHEVERRI, Rafael; RIBERO, María del Pilar. Nueva ruralidad. Visión del territorio en América Latina y el Caribe. San José, IICA, 2002.

ELIAS, Norbert; CASQUETE, Jesús. Ensayo teórico acerca de las relaciones entre establecidos y forastero. Reis. Revista Española de Investigaciones Sociológicas, Centro de Investigaciones Sociológicas. Madrid, España, n. 104, Oct.-Dec., 2003, pp. 219-251

FERRÁS SEXTO, Carlos. Los fundamentos teóricos del renacimiento rural en la sociedad postindustrial. Polígonos: Revista de geografía, n. 7, 1997, pp. 133-146.

GEERTZ, Clifford. La interpretación de las culturas. Barcelona, Gedisa, 1993.

GIARRACCA, Norma. (comp.) ¿Una nueva ruralidad en América Latina? Buenos Aires, CLACSO, 2001.

GÓMEZ PELLÓN, Eloy. Aspectos teóricos de las nuevas ruralidades latinoamericanas. Gazeta de Antropología, v. 31, n. 1, 2015, artículo 11.

GRAMMONT, Hubert C. El concepto de nueva ruralidad. En PEREZ, Edelmira (y otros) (eds.) La nueva ruralidad en América Latina. Bogotá, Universidad Javeriana, pp. 23-43.

GRAS, Carla; HERNÁNDEZ, Valeria. Modelos de desarrollo e innovación tecnológica: una revolución conservadora. Mundo Agrario. v. 17, n. 36, e028, diciembre 2016, pp. 1-27.

GRAZIANO DA SILVA, José. Perspectivas da Agricultura Alternativa. Caderno de Ciência \& Tecnologia. v. 04, n. 2, maio./ago. 1987, pp. 117-128.

HERNÁNDEZ GONZÁLEZ, Mario; MEZA HUACUJA, Ivonne (Coords.) Nueva ruralidad. Enfoques y propuestas para América Latina. CEDERSSA. México, 2006. 
HÜTER, Estefanía. Dinámicas socio-económicas del agro pampeano actual y espacios locales: una propuesta de análisis. Revista Huellas, Instituto de Geografía, EdUNLPam: Santa Rosa. v. 20, 1996, pp. 187- 208.

KAY, Cristobal. Reflections on Latin American rural studies in the neoliberal globalization period: a new rurality? Documento inédito presentado en la University of East Anglia, Norwich, Reino Unido, el 16 de abril de 2008.

LEVEAU, Carlos. ¿Contraurbanización en Argentina? Una aproximación a varias escalas con base a datos censales del período 1991 y 2001. Investigaciones Geográficas, Boletín del Instituto de Geografía. México, UNAM, n. 69, 2009, pp. 85-95.

LINCK, Thierry. El campo en la ciudad: reflexiones en torno a las ruralidades emergentes. Relaciones, v. XXII, n. 85, 2001, pp. 85-104.

LLAMBÍ, Luis. Nueva ruralidad, multifuncionalidad de los espacios rurales y desarrollo local endógeno. En Pérez, Edelmira y Farah, M. (Eds.), Desarrollo rural y nueva ruralidad en América Latina y la Unión Europea. Bogotá, PUJ, 2004.

MORILLO, María Jos; DE PABLOS, Juan Carlos. Neorrurales, la construcción de un estilo de vida. Paperpresentado VI Congreso Andaluz de Sociología. Cádiz (CD), 2012.

MUZLERA, Jose. La modernidad tardía en el agro pampeano. Sujetos agrarios y estructura productiva. Bernal, UNQ, 2013.

OTERO, Hernán. El crecimiento de la población y la transición demográfica. En Torrado, Susana (Coomp) Población y Bienestar en la Argentina del Primero al segundo Centenario. Buenos Aires, edhasa, 2007.

PICCIANI, Ana Laura. Discusiones Teóricas Sobre la Dinámica Funcional en el Vículo Espacial Urbano y Rural. Pampa. n. 14, 2016, pp. 161-180.

RIVERA, María Jesús. La Neorruralidad y sus Significados. El Caso de Navarra. Revista Internacional de Sociología (RIS), v. 67, n. 2, Mayo Agosto, 2009, pp. 413-433.

RUIZ RIVERA, Naxhelli; DELGADO CAMPOS, Javier. Territorio y nuevas ruralidades: un recorrido sobre las transformaciones de la relación campo-ciudad. Revista Eure, v. XXXIV, n. 102, agosto, 2008, pp. 77-95.

SAN AGUSTÍN, María Victoria. Paradojas Del Desarrollo: Ruralidad Versus Ciudadanía. Una Apuesta Social De Futuro ponencia presentada. XIV Simposio de Cooperativismo y Desarrollo Rural. Universidad de Zaragoza, 2001.

SANTOS, Milton. De la Totalidad al Lugar. Barcelona, Olikostan, 1996.

TRIMANO, Luciana. La Neorruralidad desde un Enfoque Antroposociocomunicacional. Miguel Hernández Communication Journal, v. 6, 2015a, pp. 195-217.

TRIMANO, Luciana. Nuevas Corrientes migratorias: desplazamiento residencial y transformación social en la ruralidad. Trabajo presentado en las XI Jornadas de Sociología de la UBA Coordenadas contemporáneas de la sociología: tiempos, cuerpos, saberes, Buenos Aires, 2015b. 
WILLIAMS, Raymond. El campo y la ciudad. Buenos Aires, Paidós, 2001.

Recebido em: 02/11/2017

Aprovado em: 30/05/2019

\section{Como citar este artigo:}

MUZLERA, José. Neorruralidad en el sudeste bonaerense. Uso del espacio y sociabilidades. Contemporânea - Revista de Sociologia da UFSCar, v. 9, n. 2, maio - agosto. 2019, pp. 563-588.

\section{Anexo}

Sistematización de entrevistas

\begin{tabular}{|c|c|c|c|c|c|c|}
\hline & & \begin{tabular}{|l} 
Piensan en \\
volverse o se \\
volvieron
\end{tabular} & Uso del pueblo & Actividad & $\begin{array}{l}\text { Relación con } \\
\text { la naturaleza }\end{array}$ & Categoría \\
\hline 1 & Mariela & No & Esf. Publ. & $\begin{array}{l}\text { Tambo, Fca. } \\
\text { Plásticos y arq. }\end{array}$ & Armónica & Ilusionado \\
\hline 2 & Hernán & No & Esf. Publ. & $\begin{array}{l}\text { Tambo y Fca de } \\
\text { plásticos }\end{array}$ & Armónica & Ilusionado \\
\hline 3 & Sandra & No & Esf. Publ. & $\begin{array}{l}\text { Vivero y } \\
\text { alojamiento rural }\end{array}$ & Armónica & Ilusionado \\
\hline 4 & Ramón & No & Pública y privada & $\begin{array}{l}\text { Changas } \\
\text { (construcción y } \\
\text { campo) }\end{array}$ & Integrada & Adaptado \\
\hline 5 & Eugenio & Sí & Dormitorio o Refugio & Jubilado & Contemplativa & Desencantado \\
\hline 6 & Julia (ex de Eugenio) & Sí & $\mathrm{NC}$ & NS & NS & Desencantado \\
\hline 7 & Pablo (h. Eugenio) & Sí & $\mathrm{NC}$ & NS & NS & Desencantado \\
\hline 8 & Soledad (h. Eugenio) & Sí & $\mathrm{NC}$ & $\begin{array}{l}\text { Música y } \\
\text { empresaria }\end{array}$ & NS & Desencantado \\
\hline 9 & Miguel & No & Pública y privada & $\begin{array}{l}\text { Changas } \\
\text { (construcción y } \\
\text { campo) }\end{array}$ & Integrada & Adaptado \\
\hline 10 & Clara & No & Esf. Publ. & Docente & NS & Ilusionado \\
\hline 11 & Carlos & No & Esf. Publ. & Sitemas & NS & Ilusionado \\
\hline 12 & Mauro & Sí & Dormitorio o refugio & Empresario & & Desencantado \\
\hline 13 & Marcela (Sra. Mauro) & Sí & Dormitorio o refugio & Ama de casa & & Desencantado \\
\hline 14 & Antonia & No & Esf. Publ. & Ama de casa & Contemplativa & Ilusionado \\
\hline 15 & Roberto & No & Esf. Publ. & Ing. Agr. & Contemplativa & Ilusionado \\
\hline 16 & Arturo & Sí & Dormitorio o refugio & Jubilado & Contemplativa & Desencantado \\
\hline 17 & Teresa (Sra. Arturo) & Sí & Dormitorio o refugio & NS & NS & Desencantado \\
\hline 18 & Federica & No & Dormitorio o refugio & Jubilada & Integrada & $x+* *$ \\
\hline
\end{tabular}

